\title{
Is Economical and Social Development Really Linked with the Shift of Labour from Secondary to Tertiary Sector? Evidence from the Italian Case
}

\author{
Enrico Ivaldi ${ }^{1} \&$ Riccardo Soliani ${ }^{1}$ \\ ${ }^{1}$ Department of Economics University of Genova, Italy \\ Correspondence: Enrico Ivaldi, Department of Economics University of Genova, via Vivaldi 5, 16126, Genova, \\ Italy. E-mail: enrico.ivaldi@unige.it
}

Received: February 19, 2014

Accepted: March 4, 2014

Online Published: April 25, 2014

doi:10.5539/ijef.v6n5p26

URL: http://dx.doi.org/10.5539/ijef.v6n5p26

\begin{abstract}
In the present paper, first, we have carried out a study about regional deprivation in Italy and tested it with a variable test (in this case, life expectancy at birth) to estimate its goodness. RDI index is linked with life expectancy at birth about $60 \%$.

Then we have divided Italian Regions into five different classes, from the "best" (less deprived) to the "worst" (much deprived) one. In each group we have examined the working population in every sector and the share of labourers in primary, secondary and tertiary sector, in order to verify the usual argument according to which growth and socio-economic development go with the boost of tertiary. The tertiary sector is determined according to ISTAT definition, which includes public administration. However, in a further step of our analysis we separate private from public tertiary. The evolution towards the advanced "post-industrial" society is apparently proved wrong in this case.
\end{abstract}

Keywords: deprivation in Italy, economic sectors development, factorial analysis, social economy

\section{Introduction and Objectives}

The faster long run growth of the tertiary sector with respect to the secondary is deemed the hallmark of the advanced countries. However, looking at regional development, this can be not always true.

Our propose is to test this evolution in the case of Italian regional development. Therefore we calculate social and economic deprivation in each region and compare it with the shares of labourers in different sectors.

Deprivation indexes highlight the characteristics of the population living in a defined geographical area by measuring the similarities and dissimilarities of individuals belonging to the whole group. They are simple, inexpensive tools generally made up of census indicators easily available and combined using different types of statistical analysis. For this reason, deprivation indexes, after being developed in the United Kingdom with the seminal works of Jarman (Jarman, 1983, 1984), to measure the workload of General Practitioners in England and Wales, Townsend (Townsend, 1987; Townsend et al., 1988) to analyse health measures in the Northern regions of the UK with particular reference to inequalities in health and Carstairs (Carstairs \& Morris, 1991), for evaluating inequalities in health within Scotland, have been widely used, spreading across many other countries, such as, between others, Spain (Benach et al., 1999), to measure excess mortality through deprivation, Ireland (Kelleher et al., 2002), with reference also to voting behaviour, the Netherlands (Smith et al., 2002), New Zealand (Hales et al., 2003) and Italy (Brenna, 2007; Costa et al., 2009; Testi \& Ivaldi, 2009, 2011) to measure different level of deprivation and share public resources.

\section{Methodology}

We have constructed an index based on currently available data, which come directly from certified sources. It does not require ad hoc surveys, avoiding additional costs, and can be updated in a simple and continuous manner (Jarman, 1983, 1984; Gordon \& Pantazis, 1997).

We have conducted a preliminary test on data provided by the most relevant international research bodies. The analysis has focused on a set of variables consistent with those usually selected by current literature (Townsend, 1987; Carstairs \& Morris, 1991; Noble et al., 2003; Guio, 2009; Whelan et al., 2010). 
To simplify the interpretation, one can group variables into a small number of dimensions according to their fundamental characteristics, by means of the analysis of empirical data, or on the basis of subjective criteria. In our case, we have chosen the first method, using factorial analysis. It is a statistical technique which represents the set of the identified variables in terms of a lower number of underlying variables, so simplifying complex data. Factorial analysis conveys information in the variance/co-variance matrix, trying to identify the latent dimensions of the phenomenon (Dillon \& Goldstein, 1984; Stevens, 1986). It explains the maximum possible variance of the variables included in the original information matrix. Thus we obtain a set of new variables through a linear transformation of the original ones, thereby reducing the number of variables needed to describe the phenomenon.

For example, if we have $p$ variables $X_{1}, X_{2}, \ldots, X_{j}, \ldots, X_{p}$ measured on a sample of $n$ subjects, the $j$-th variable may be written as the linear combination of $m$ factors $F_{1}, F_{2}, \ldots, F_{m}$ where $m<p$ (Härdle \& Simar, 2003). Then

$$
X_{j}=k_{j 1} F_{1}+k_{j 2} F_{2}+\ldots+k_{j m} F_{m}+e
$$

where:

$k_{j k}$ are the factorial scores for the variable $j(j=1,2,3, \ldots, \mathrm{p})$;

$e$ is the part of the variable $X_{i}$ not explained by the factors.

Since the variables can be saturated by differing factors in almost the same way, the problem of the rotation of factors rises. The rotation brings about the reduction of the weight of the factors that were comparatively "lighter" in the first step of the analysis, along with the increase of the weight of the factors that were comparatively "heavier" (note that here the absolute value is concerned) (Krzanowski \& Marriott, 1995). Indeed, in a non-rotation solution any variable is explained by two or more common factors, whereas in a rotation solution any variable is explained by a single common factor (Johnson \& Wichern, 2002). With reference to this case study, subsequent tests, using differing algorithms for extraction and rotation, have shown the real stability of the factors extracted (Kaiser, 1958).

According to this methodology, the indicators obtained are to be compared to a variable test to estimate their goodness. In our study, we use life expectancy at birth. The effectiveness of the index is measured by calculating the value of the Pearson correlation coefficient between indicators and variable test.

In order to group the regions, identify classes and discriminate amongst different levels of inequality, the literature suggests homogenous groupings and either breaking down the distribution of indices on the basis of parameters, or using population quintiles (Jarman, 1984; Townsend et al., 1988; Carstairs \& Morris, 1991; Carstairs, 2000).

We have decided to use population quintiles. Thus the share of laborers in one class has approximately the same weight as in another, and any distortion due to the different demographic relevance of Italian regions is avoided.

The index distribution has been divided into five classes, class 1 identifying the regions with the lowest deprivation. Each class is correlated with the correspondent value of life expectancy.

Then we disaggregate the labourers according to their respective productive sector, to check the prevailing sector of activities in the regions included in each class. Note that such disaggregation must be done considering only working population. On the other hand the classes have been established on the basis of the whole resident population. This does not cause distortion; indeed deprivation affects both workers and their families, and even the case of families of unemployed represents a form of deprivation. The tertiary sector is defined according to ISTAT definitions, which include the public administration. However at the end of our analysis we separate private from public tertiary.

Our goal is to verify the usual argument according to which the boost of tertiary goes with growth and socio-economic development.

\section{Results}

The seven variables, selected according to the mentioned methodology, are indicated below:

$X_{I}=\%$ of unemployed people compared to active (Unemployment rate);

$X_{2}=\%$ of households living in rented houses (Dwellers in rented houses);

$X_{3}=$ average number of people per room (Overcrowding);

$X_{4}=\%$ of people with secondary education (8 years) or lower (Low education level);

$X_{5}=$ inequality in the income distribution (Gini coefficient); 
$X_{6}=$ single-parent families;

$X_{7}=$ ethnic minorities.

The factorial analysis reveals that the variables are distributed on two principal components able to explain the variance at $71 \%$ of the total variability of the model (Table 1 ).

Table 1. Factor analysis score and total variance explained

Table 1a. Rotated component matrix(a)

\begin{tabular}{lcc}
\hline & \multicolumn{2}{c}{ Component } \\
\hline Ethnic minorities & 1 & 2 \\
Low education level & $\mathbf{- , 9 1 7}$ &,- 210 \\
Unemployment rate & $\mathbf{, 8 5 8}$ &, 055 \\
Overcrowding & $\mathbf{, 8 3 7}$ &, 375 \\
Gini coefficient &, 295 & $\mathbf{, 8 0 9}$ \\
Single-parent families &, 408 & $\mathbf{, 7 5 9}$ \\
Dwellers in rented houses &, 025 & $\mathbf{, 6 1 8}$ \\
\hline
\end{tabular}

Extraction Method: Principal Component Analysis. Rotation Method: Varimax with Kaiser Normalization. a Rotation converged in 3 iterations.

Table $1 \mathrm{~b}$. Total variance explained

\begin{tabular}{lccc}
\hline Component & \multicolumn{3}{c}{ Rotation Sums of Squared Loadings } \\
& Total & \% of Variance & Cumulative \% \\
\hline 1 & 2,822 & 40,313 & 40,313 \\
2 & 2,130 & 30,427 & 70,741 \\
\hline
\end{tabular}

Extraction Method: Principal Component Analysis.

The index spans from -1,369 in Veneto, to 1,893 in Campania: if it is negative, economic and social development are better than average; the opposite if it is positive (Table 2).

Table 2. RDI Index

\begin{tabular}{lclc}
\hline Region & Regional Deprivation Index (RDI) & Region & Regional Deprivation Index (RDI) \\
\hline Veneto & $-1,369$ & Marche & $-0,278$ \\
Friuli-Venezia Giulia & $-1,176$ & Valle d'Aosta & 0,027 \\
Trentino & $-1,085$ & Lazio & 0,300 \\
Umbria & $-1,055$ & Molise & 0,699 \\
Emilia-Romagna & $-0,983$ & Calabria & 0,731 \\
Liguria & $-0,729$ & Basilicata & 0,819 \\
Lombardia & $-0,545$ & Puglia & 1,155 \\
Abruzzo & $-0,508$ & Sardegna & 1,231 \\
Toscana & $-0,461$ & Sicilia & 1,668 \\
Piemonte & $-0,332$ & Campania & 1,893 \\
\hline
\end{tabular}

RDI index is linked with life expectancy at birth. The Pearson correlation coefficient is rather high $(-0,592)$ : this means that about $60 \%$ of life expectancy gradient is potentially explained by these socio-economic conditions.

The distribution of RDI index has been divided into five classes: class 1 identifies the countries with the best socio-economic conditions (and the best life expectancy), whilst class 5 includes countries characterized by the highest RDI index value (and the worst life expectancy) (Table 3). 
Table 3. RDI classes and life expectancy

\begin{tabular}{clc}
\hline Class & Region & Life expectancy at birth \\
\hline 1 & Veneto, Friuli-Venezia Giulia, Trentino Alto Adige, Umbria, Emilia-Romagna & 82,56 \\
2 & Liguria, Lombardia, Abruzzo & 82,26 \\
3 & Toscana, Piemonte, Marche, Valle d'Aosta & 82,24 \\
4 & Lazio, Molise, Calabria, Basilicata, Puglia & 82,17 \\
5 & Sardegna, Sicilia, Campania & 81,14 \\
\hline
\end{tabular}

In Figure 2 the five classes are put in evidence with different graphic signs.

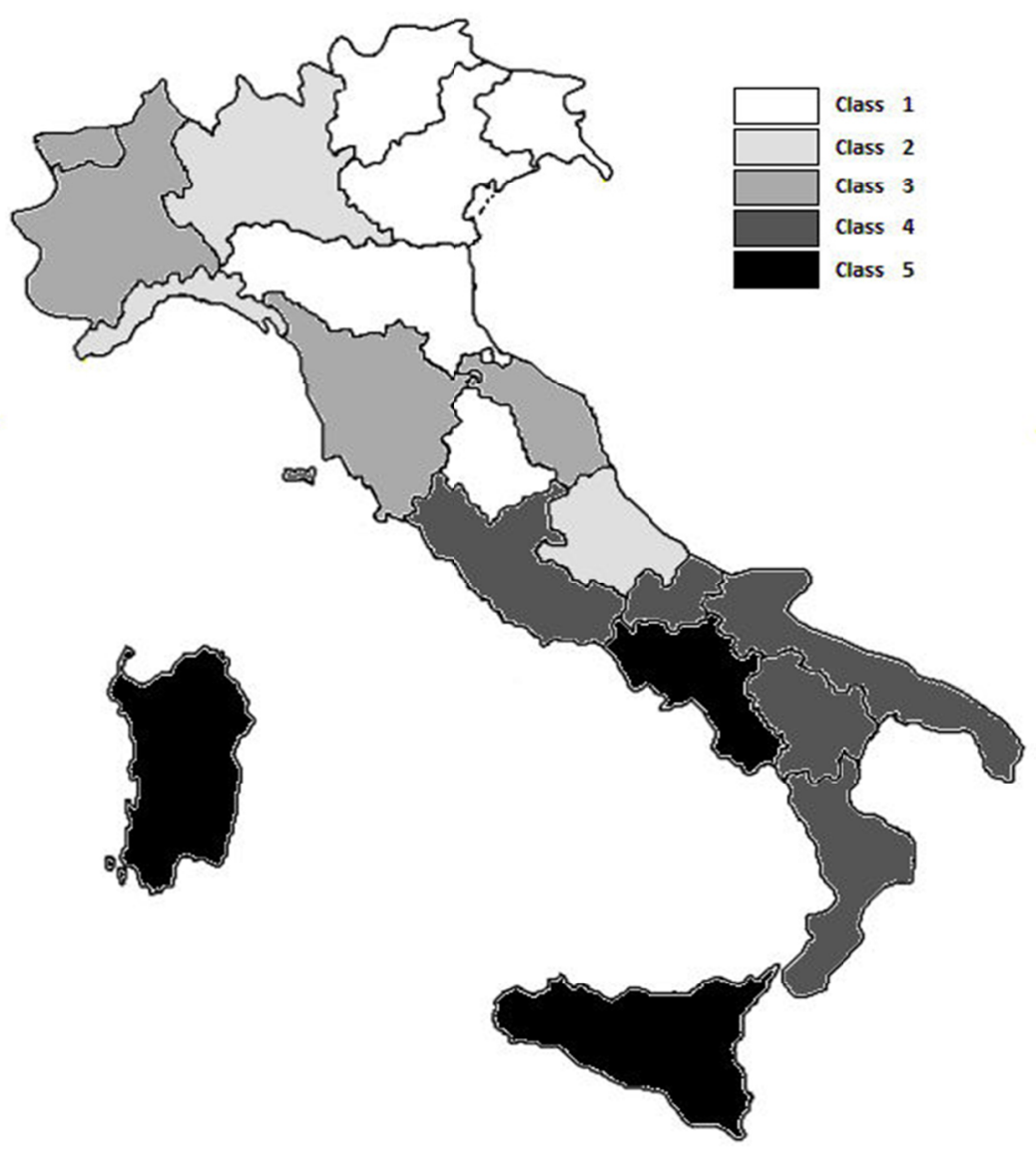

Figure 2. RDI classes and regions

The first class includes the North Eastern Italy and Emilia Romagna. Here the Italian district model is still granting a high standard of life. A large part of the first class corresponds to the areas labelled by CENSIS (Centro Studi Investimenti Sociali-Observatory on Social Investment) as "Industrial Platform" and "Multifunctional Network of Competitive Manufacture" (ABI-CENSIS, 2014). Also Umbria belongs to this class, mainly due to its high level of education and low inequality of income; it should be noted also the relevance of ethnical minorities, which can be explained by the University of Perugia and important institutions of Catholic Church. In the second class are Liguria, Lombardia and Abruzzo. Here we have areas of old industrialisation (Liguria and Lombardia) which still allows a good standard of living and Abruzzo, where inequality in income is the lowest in Italy and the percentage of households living in rented houses is very low. Valle d'Aosta, Piemonte, Toscana e Marche form the third class. The four regions are heterogeneous. The old industry in Piemonte is declining without any significant balance by new models of growth. On the other hand Toscana and Marche are based on light industry, small firms and tourism. Valle d'Aosta is often considered a 
region with good quality of life and has very high income per-capita; but it has also low education, relevant inequality in income and many single-parent families. This explains its comparatively low score. Lazio belongs to the fourth class which includes also four regions in Southern Italy. The bad performance of Lazio (however its ranking is approximately so far from Valle d'Aosta as from Molise) mainly depends on the dramatic inequality in income; furthermore, it has the highest number of single parent families. Finally, the most deprived is the class 5 , including Campania, Sicilia and Sardegna. Campania has relevant overcrowding. Sardegna shows the highest unemployment and the lowest education. Sicilia is the most unequal in income region. Remarkably, also the cited research by CENSIS singles out their territorial characters as social and economic imbalance, rural economy with low growth and unstructured pattern industry-trade-tourism.

Life expectancy of each class decreases smoothly from the first $(82,56)$ to the forth class $(81,14)$ and slopes steeply down to the fifth. The difference between the top and the bottom is about 2 years and 6 months. Note that between forth and fifth class the gap is about one year (Table 3).

Then we disaggregate labourers in their different productive sectors, following ISTAT categories. The first sector is composed by agriculture, mines and fishing. The second sector includes industry and building. As is known, the third sector is heterogeneous, since we find there both advanced activities (banking, ICT, finance, management consultants) and other business, e.g., small shops and personal services. It includes also public administration.

Labourers in the first sector increase almost continuously from the first to the fifth class with a marked gap between third and forth class; also the employment in the secondary sector decreases dramatically from class 3 to class 4. Quite unexpectedly, the share of labourers employed in the tertiary sector rises from the first to the fifth class (Table 4a); but the rise is less evident if one excludes public administration (Table 4b).

Table 4a. RDI class and productive sector

\begin{tabular}{cccc}
\hline Class & Agricultural and fishing & Industry & Tertiary \\
\hline 1 & $3,21 \%$ & $32,63 \%$ & $64,16 \%$ \\
2 & $2,07 \%$ & $31,17 \%$ & $66,75 \%$ \\
3 & $3,27 \%$ & $29,34 \%$ & $67,39 \%$ \\
4 & $5,70 \%$ & $19,38 \%$ & $74,92 \%$ \\
5 & $5,96 \%$ & $18,12 \%$ & $75,92 \%$ \\
\hline
\end{tabular}

Table 4b. RDI class and productive sector

\begin{tabular}{ccccc}
\hline Class & Agricultural and fishing & Industry & Tertiary (P.A. Only) & Tertiary (excluding P.A.) \\
\hline 1 & $3,21 \%$ & $32,63 \%$ & $16,40 \%$ & $47,76 \%$ \\
2 & $2,07 \%$ & $31,17 \%$ & $15,05 \%$ & $51,70 \%$ \\
3 & $3,27 \%$ & $29,34 \%$ & $15,96 \%$ & $51,43 \%$ \\
4 & $5,70 \%$ & $19,38 \%$ & $21,48 \%$ & $53,44 \%$ \\
5 & $5,96 \%$ & $18,12 \%$ & $24,39 \%$ & $51,53 \%$ \\
\hline
\end{tabular}

\section{Discussion}

In our classification, life expectancy decreases uniformly. There is a sharp divide between forth and fifth class, the last one including three regions of Southern Italy. The model of "Italy at different speeds" begins to appear.

The first immediate result is the uniform fall of the share of industry from the first to the fifth class. Particularly there is a drop between the third and the fourth class. Note that fourth and fifth class include the Southern Italian regions except Abruzzo, where the district model partly survives (Becattini 2003; Becattini et al., 2003) and perhaps also the relevance of black economy is less marked.

The divide between the third and the fourth class is confirmed if we look at the share of employees in the primary sector, which increases significantly.

Furthermore the overall tertiary sector soars uniformly, also in this case with a step between the third and the forth class. However the split is even wider if we consider the difference between private and public tertiary. In this case it appears the utmost relevance of the weight of tertiary in the fifth class and also in the forth, where Rome is included. The usual interpretation of the state as employer of last resort is supported especially for the fifth class, taking into account also the high rate of unemployment in Southern Italy. The slightly high share in 
the first class could be due to the presence of Army in the North East.

The dimension of the private tertiary sector does not show any significant trend, but there are a couple of noteworthy cases. The lowest percentage is in the first class, where industry is relevant. The small firm system prevailing in Veneto and Emilia Romagna tends to internalise several tertiary functions that big firms are likely to outsource. The development of big firms makes it possible the growth of advanced services provided by enterprises of the tertiary; such evolution can be found in the second class where Lombardia is the biggest industrial region of Italy.

The highest percentage is in the fourth class; it might be explained by the great number of lawyers in Lazio, Calabria and Puglia. Rome is also the capital of Italian entertainment and has a big share of labourers employed in tourism. Furthermore, important Italian tertiary companies, like Trenitalia or Alitalia, are established in Rome.

\section{Conclusions}

Our paper shows that the common picture of the Italian economy running at different speeds is confirmed also if we look at social development. Italian population may be divided into 5 equal classes, classified according to the respective RDI. Their ranking partly mirrors the distribution of labourers between the three sectors of economy, with the agriculture's increasing weight and industry's decreasing proportion as we pass from the first to the fifth class (the most deprived). Deprivation is accompanied by the comparatively low industrial development.

The behaviour of the tertiary is different, since it increases its proportion as long as deprivation rises. The evolution towards the very advanced "post-industrial" society is apparently proved wrong in this case. We try to explain the oddity, splitting the sector into private and public tertiary. This allows us to single out the peculiar role of the State as "employer of last resort", which absorbs unemployment in the most deprived regions. On the other hand, the private services do not show any clear trend. We can only guess that a few specific causes (tourism, entertainment, institutions ...) engender the high record in the fourth class, whereas the Italian industrial structure, based on small firms localised into North East and big firms in the North West, might explain the result of the first and the second class. Further work should be done to grasp the relation between advanced tertiary and social conditions.

\section{Acknowledgements}

We wish to thank prof. Bruno Soro for his comments and suggestions and dr. Alessia Di Gennaro for her help in collecting data. Usual caveat applies.

\section{References}

ABI-CENSIS. (2014). Territorio, Banca, Sviluppo. Roma.

Becattini, G. (2003). Industrial districts. A new approach to industrial change. Cheltenham: Edward Elgar.

Becattini, G., Bellandi, M., Dei Ottati, G., \& Sforzi, F. (2003). From industrial districts to local development. Cheltenham: Edward Elgar.

Benach, J., \& Yasui, Y. (1999). Geographical patterns of excess mortality in Spain explained by two indices of deprivation. Journal of Epidemiology and Community Health, 53, 423-431. http://dx.doi.org/10.1136/jech.53.7.423

Brenna, E. (2007). The weighting of capitation on the basis of deprivation factors. Tips for Italy from the Scottish. Politiche Sanitarie, 2, 65-76.

Carstairs, V. (2000). Socio-economic factors at area level and their relationship with health. In P. Elliott, J. Wakefield, N. Best, \& D. Briggs (Eds.), Spatial epidemiology methods and applications (pp. 51-68). Oxford University Press.

Carstairs, V., \& Morris, R. (1991). Deprivation and health in Scotland. Aberdeen University Press.

Costa, G., Cislaghi, C., \& Caranci, N. (2009). The social inequalities in health. Problems of definition and measurement. Salute e Società, Franco Angeli, 1, 1-6, (In Italian).

Dillon, W., \& Goldstein, M. (1984). Multivariate analysis method and application. New York, NY: Wiley.

Gordon, D., \& Pantazis, C. (1997). Breadline Britain in the 1990s. Ashgate: Ashgate Publishing Limited.

Guio, A. C. (2009). What can be learned from deprivation indicators in Europe? European Commission, Methodologies and Working Papers, ISBN 9789279123085.

Hales, S., Black, W., Skelly, C., Salmond, C., \& Weinstein, P. (2003). Social deprivation and the public health risks of community drinking water supplies in New Zealand. Journal of Epidemiology and Community 
Health, 57, 581-583. http://dx.doi.org/10.1136/jech.57.8.581

Härdle, W., \& Simar, L. (2003). Applied multivariate statistical analysis. Method \& Data Technologies. http://dx.doi.org/10.1007/978-3-662-05802-2

Ivaldi, E., \& Testi, A. (2010). Genoa Index of Deprivation (GDI): An index of material deprivation for geographical areas. In C. M. Baird (Ed.), Social indicators: Statistics, trends and policy development. New York, NY: Nova Publisher.

Ivaldi, E., \& Testi, A. (2011). Socio-economic conditions and health in Europe: A comparison among the $27 \mathrm{EU}$ Countries. In J. D. Rowsen, \& A. P. Eliot (Eds.), Social Inequalities. New York, NY: Nova Publisher.

Jarman, B. (1983). Identification of underprivileged areas. British Medical Journal, 286, 1705-1709. http://dx.doi.org/10.1136/bmj.286.6379.1705

Jarman, B. (1984). Underprivileged areas: Validation and distribution of scores. British Medical Journal, 289, 1587-1592. http://dx.doi.org/10.1136/bmj.289.6458.1587

Johnson, R. A., \& Wichern, D. W. (2002). Applied multivariate statistical analysis (5th ed.). Englewood Cliffs: Prentice-Hall.

Kaiser, H. F. (1958). The varimax criterion for analytic rotation in factor analysis. Psychometrika, 23, 187-200. http://dx.doi.org/10.1007/BF02289233

Kelleher, C., Timoney, A., Friel, S., \& McKeown, D. (2002). Indicators of deprivation, voting patterns and health status at area level in the Republic of Ireland. Journal of Epidemiology and Community Health, 56, 36-44. http://dx.doi.org/10.1136/jech.56.1.36

Krzanowski, W. J., \& Marriott, F. H. C. (1995). Multivariate Analysis. Part 2. London: Arnold.

Noble, M., Smith, G., Wright, G., Dibben, C., Loyd, M., Ratcliffe, A., \& Anttila, C. (2003). Scottish indices of deprivation 2003. Edinburgh: Scottish Executive.

Smits, J., Westert, G., \& Van Den Bos, G. (2002). Socioeconomic status of very small areas and stroke incidence in the Netherlands. Journal of Epidemiology and Community Health, 56, 637-640. http://dx.doi.org/10.1136/jech.56.8.637

Soliani, R., Di Gennaro, A., \& Ivaldi, E. (2012a). An index of the quality of life for European country: Evidence of deprivation from EU-Silc data. Review of Economics \& Finance, 2(2), 1-14. Toronto: Better Advances Press.

Soliani, R., Di Gennaro, A., \& Ivaldi, E. (2012b). How deprivation affects life expectancy in France and Italy: Comparative evidence from a factorial analysis, in Socioeconomic status and health implications (pp. 145162). Hauppauge, New York, NY: Nova Publisher.

Stevens, J. (1986). Applied multivariate statistics for the social sciences. Hillsdale: Lawrence Erlbaum Associates.

Testi, A., \& Ivaldi, E. (2009). Material versus social deprivation and health: a case study of an urban area. The European Journal of Health Economics, 3, 323-328. http://dx.doi.org/10.1007/s10198-008-0136-z

Testi, A., \& Ivaldi, E. (2011). Measuring progress in health through deprivation indexes. Review of Economics and Finance, 2, 9-57. Toronto: Better Advances Press.

Townsend, P. (1987). Deprivation. Journal of Social Policy, 2, 125-146. http://dx.doi.org/10.1017/S0047279400020341

Townsend, P., Phillimore, P., \& Beattie, A. (1988). Health and deprivation: Inequality and the North. London: Croom Helm.

Whelan, C. T., Lucchini, M., Pisati, M., \& Maitre, B. (2010). Understanding the socio-economic distribution of multiple deprivation: An application of self-organising maps. Research in Social Stratification and Mobility, 3, 325-342. http://dx.doi.org/10.1016/j.rssm.2010.03.003

\section{Copyrights}

Copyright for this article is retained by the author(s), with first publication rights granted to the journal.

This is an open-access article distributed under the terms and conditions of the Creative Commons Attribution license (http://creativecommons.org/licenses/by/3.0/). 